\title{
Deformation and fracture of aluminium foams
}

\author{
O.B. Olurin, N.A. Fleck*, M.F. Ashby \\ University of Cambridge, Department of Engineering, Trumpington Street, Cambridge CB2 1PZ, UK
}

Received 20 December 1999; received in revised form 17 April 2000

\begin{abstract}
The tensile and compressive properties and the fracture resistance of two aluminium alloy foams have been measured. The yield strength, unloading modulus and toughness increase with relative density in such a manner that the closed cell foams of this study behave as open cell foams. These relationships can be described adequately by power law fits. Experimental results, when compared with theoretical models based on idealised foam structures, reveal unexpected discrepancies. We conclude that they are caused by morphological defects in the microstructures of the foams, the effects of which were not included in the models. Tests on samples with deep sharp notches show that the tensile and compressive strengths are notch-insensitive. Fracture toughness measurements show an $R$-curve behaviour. This is analysed in terms of the underlying microstructure - the major cause of the $R$-curve was observed to be the development of crack bridging ligaments behind the crack tip. The compact tension specimens employed were sufficiently small for the uncracked ligaments to suffer plastic yielding during the fracture tests. The crack bridging response was quantified in terms of the normal traction versus plastic displacement curve; the area under this curve for a deep double edge-notched specimen is approximately equal to the measured steady state toughness. The accuracy of an existing micromechanical model for the fracture toughness of brittle open cell foams is assessed, and a new toughness model for ductile foams is derived. (C) 2000 Elsevier Science S.A. All rights reserved.
\end{abstract}

Keywords: Aluminium foams; Tensile and compressive properties; Fracture toughness

\section{Introduction}

Recent developments in foaming technology have made metallic foams a commercial possibility. Metallic foam manufacturing techniques include solid state powder methods, gas-blowing processes, liquid state processing, casting with a blowing agent and metal deposition onto a polymer 'precursor' [1-9]. This paper reports a study of the monotonic deformation and fracture properties of two closed cell aluminium alloy foams, Alporas ${ }^{1}$ and Alcan ${ }^{2}$. The Alcan foam is made in the liquid state by blowing with air or nitrogen,

\footnotetext{
* Corresponding author. Tel.: + 44-1223-332650; fax: + 44-1223332662 .

E-mail address: naf1@eng.cam.ac.uk (N.A. Fleck).

${ }^{1}$ Shinko wire company Ltd., 10-1, Nakahama-machi, Amagasakishi, 660 Japan.

${ }^{2}$ Alcan International Ltd., Box 8400, Kingston Ontario, K7L 5L9, Canada.
}

whereas Alporas is produced by stirring a blowing agent (titanium hydride) within the melt.

\section{The understanding of foam modulus, strength and toughness}

We consider a closed cell foam of density $\rho$ made from solid aluminium alloy of density $\rho_{\mathrm{s}}$. First, we summarise the current theoretical understanding of the relation between the basic mechanical properties and the relative density $\bar{\rho}\left(\equiv \rho / \rho_{\mathrm{s}}\right)$ of metallic foams. Since foams can suffer large plastic strains, it is important to define stress and strain precisely: we shall employ nominal measures of stress and strain throughout.

When a closed cell foam is deformed the cell edges bend, and the cell faces carry membrane stresses. The contribution from cell face stretching to the overall stiffness and strength of the foam is by a term that is linear in the relative density $\bar{\rho}$, while the contribution from cell edge bending is non-linear in the relative density. The result, as Gibson and Ashby [1] show, is 
that the yield strength of a metallic foam $\sigma_{\mathrm{pl}}$ in tension or compression is related to the yield strength of the cell wall material $\sigma_{\mathrm{y}}$ by:

$\frac{\sigma_{\mathrm{pl}}}{\sigma_{\mathrm{y}}}=0.3 \phi^{3 / 2} \bar{\rho}^{3 / 2}+(1-\phi) \bar{\rho}$

where $\phi$, the 'distribution constant', is the fraction of solid in the foam that is contained in cell edges $(\bar{\rho} \leq$ $\phi \leq 1)$. The remaining fraction $(1-\phi)$ occupies the cell face. Similarly, the modulus $E$ of the foam is related to the elastic modulus of the cell wall material $E_{\mathrm{s}}$ according to:

$\frac{E}{E_{\mathrm{s}}}=\phi^{2} \bar{\rho}^{2}+(1-\phi) \bar{\rho}$

Estimates for $\sigma_{\mathrm{pl}} / \sigma_{\mathrm{y}}$ and $E / E_{\mathrm{s}}$ for the limiting case of open cell foams are obtained by setting the distribution constant $\phi=1$; those for closed cell foams with negligible cell edges are given by $\phi=0$.

The geometry of the cells changes with imposed strain. An extreme manifestation of this is the sharp increase in the compressive stress versus strain curve at a nominal compressive strain, termed the densification strain, which is given in [1] by:

$\varepsilon_{\mathrm{D}}=\alpha-\beta \bar{\rho}$

For non-metallic cellular foams [1] it has been found that $\alpha \approx 0.8$ and $\beta=1.4$, whereas for currently available metallic foams [10], $\alpha \approx 0.8$ and $\beta=1.4-2.0$.

The fracture toughness of foams is less well documented. Earlier work of Gibson and Ashby [1] has demonstrated that the fracture toughness $K_{\text {IC }}$ of brittle open cell foams depends upon the relative density $\bar{\rho}$, the fracture strength (or yield strength) of the cell wall material $\sigma_{\mathrm{y}}$, and the cell size $\ell$, according to

$K_{\mathrm{IC}}=0.65 \sigma_{\mathrm{y}}(\pi \ell)^{1 / 2} \rho^{3 / 2}$

A number of experimental investigations $[1,11,12]$ on brittle foams support the accuracy of Eq. (4).

Sugimura et al. [13] have conducted notched bend tests to investigate the crack growth response of a closed cell aluminium alloy foam (trade name 'Alporas'), processed by gas-releasing particle decomposition in the melt. Fracture measurements indicated that crack growth occurs along the cell faces by a mechanism analogous to the plastic tearing of thin sheets. The resulting steady state fracture toughness $K_{\text {ss }}$ was estimated to be

$K_{\mathrm{ss}} \approx\left(E_{\mathrm{s}} \sigma_{\mathrm{y}} \ell\right)^{1 / 2} \bar{\rho}^{3 / 2}$

where $E_{\mathrm{s}}$ is the Young's modulus of cell wall material, and $\ell$ is the cell size. More recently, using compact tension specimens, McCullough et al. [14] have measured the crack initiation toughness and the $R$-curves for another type of closed cell aluminium alloy foams (trade name 'Alulight'), processed by gas-releasing par- ticles in semi-solids. They showed that the development of a crack bridging zone behind the crack tip plays a major role in the increased crack growth resistance with crack advance. The crack bridging law of the foam has also been measured independently by $\mathrm{McCul}-$ lough et al. [14] via deep notch tests, and it was confirmed that the area beneath the bridging traction versus extra displacement curve approximately equals the steady state crack propagation toughness $J_{s s}$. These experiments support the use of a Dugdale-type line spring model for crack growth.

In order to assess the accuracy of existing predictions for the properties of metallic foams it is important to have reliable data for the cell wall properties $\rho_{\mathrm{s}}$, $E_{\mathrm{s}}, \sigma_{\mathrm{y}}$ and $\phi$ for foams over a wide range of relative density. In this study we measure the cell walls properties independently, and we then compare the predictions of Eqs. (1)-(4) with measured data.

\section{Experimental procedure}

\subsection{The materials}

Two closed cell foams were investigated in this study. The first, Alporas, consists of $0.4-2$ wt. $\%$ of calcium to enhance viscosity and $<2 \mathrm{wt} . \%$ of titanium hydride powder added as a foaming agent. The titanium released from the foaming agent and the calcium remain in the aluminium after the processing has been completed: the cell walls contain the oxides $\mathrm{CaO}$ and $\mathrm{CaAl}_{2} \mathrm{O}_{4}$. The Alporas foam was tested in the asfoamed condition without a cold rolling pre-treatment. (An alternative version of Alporas foam is rolled in order to burst the cell walls and increase its noise absorption properties.) The second, Alcan, is a cast aluminium alloy, A356 (7 wt.\% $\mathrm{Si}$ and $0.3 \mathrm{wt} \% \mathrm{Mg}$ ), stabilised by about $5-15$ vol.\% $\mathrm{SiC}$ particles (average size between 1 and $20 \mu \mathrm{m}$ ). The Alcan foams are notable for their large cell size, on the order of 5-15 $\mathrm{mm}$; they are cast into plates of thickness $40-75 \mathrm{~mm}$ and possess a density gradient through the thickness [15].

Samples of the foams were sectioned by electro-discharge machining, infiltrated with a coloured epoxy, polished and then scanned digitally into a $2 \mathrm{D}$ quantitative image analysis system using a video camera [16]. Typical microstructures are shown in Fig. 1. Digital analysis of the binary images was used to characterise the cell shape, relative density and cell wall thickness. Table 1 lists the results.

\subsection{Mechanical testing strategy}

Uniaxial tension and compression stress-strain tests and fracture toughness tests were performed at room 
(a)

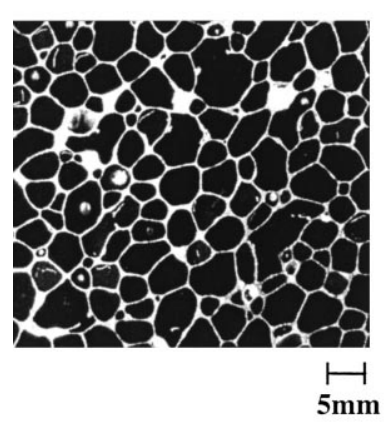

(b)

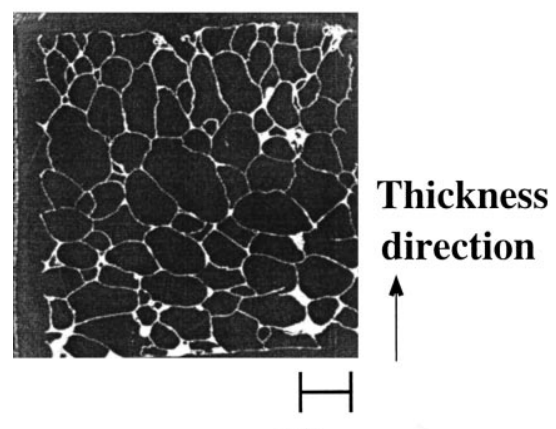

$10 \mathrm{~mm}$

Fig. 1. Optical cross-section of (a) Alporas metallic foam, and (b) Alcan metallic foam in the $\mathrm{L}-\mathrm{T}$ orientation.

temperature in displacement control using a servo-hydraulic testing machine. Each specimen was weighed to four significant figures to determine its density $\rho$, and hence the relative density $\bar{\rho}$. During compressive loading, the loading platens were lubricated with PTFE spray in order to minimise friction between the platens and the specimen.

Tests were performed at a rate of 0.01 and $0.1 \mathrm{~mm}$ $\mathrm{s}^{-1}$ for tensile and compressive loading, respectively. Details of the testing procedure for uniaxial tension and compression, and for fracture toughness follow.

\subsection{Uniaxial tension and compression tests}

Tensile tests were performed on dog-bone specimens with gripped faces reinforced with epoxy. Specimens of uniform rectangular cross-section were used for the compression tests. All specimens were sized to ensure that they contained a minimum of seven cells per side, in order to ensure that the measured properties are representative of those of the bulk material $[17,18]$. Tensile and compressive tests were performed on both the Alcan and Alporas foams in the longitudinal (L), transverse (T) and through-thickness (TT) directions. For the case of Alcan foam, the higher density skins were removed to a depth of $5 \mathrm{~mm}$ prior to the testing in the $\mathrm{L}$ and $\mathrm{T}$ directions.

\subsection{Uniaxial tension and compression tests in the presence of deep notches}

Deep double edge-notch specimens of Alporas foam (relative density $\bar{\rho}=0.11$, length $=$ width $=60 \mathrm{~mm}$ ) and Alcan foam $(\bar{\rho}=0.075$, length $=$ width $=60 \mathrm{~mm})$ were prepared in the longitudinal direction to determine the notch sensitivity. The measured net section stress versus plastic displacement across the ligament was also measured, and used subsequently as the cohesive zone law in a crack bridging model. The notches were electrical discharge machined into the specimens, and were of root diameter $0.1 \mathrm{~mm}$, and height 0.1 and $7 \mathrm{~mm}$ for the tensile and compressive test specimens, respectively. Clip gauges of gauge length $8 \mathrm{~mm}$ straddled the midplane of the specimen, and were used to measure the plastic displacement at the net section due to the accumulation of plasticity and microcracking.

\subsection{Fracture toughness tests}

Fracture toughness tests were performed on standard compact tension specimens of width, $W=100-200 \mathrm{~mm}$ and initial notch length $a_{0} / W=0.30$ for the Alporas foam, and of width $W=150-300 \mathrm{~mm}$ and $a_{0} / W=0.30$ for the Alcan foam. The starter notch was cut into the

Table 1

The relative density and dimensions of the metallic foams panels

\begin{tabular}{llllll}
\hline Material & Panel thickness $B(\mathrm{~mm})$ & $\begin{array}{l}\text { Average density } \rho \\
\left(\mathrm{Mgm}^{-3}\right)\end{array}$ & $\begin{array}{l}\text { Relative density } \\
\bar{\rho}\end{array}$ & $\begin{array}{l}\text { Mean cell size } \ell \\
(\mathrm{mm})\end{array}$ & $\begin{array}{l}\text { Mean wall thickness } t \\
(\mathrm{~mm})\end{array}$ \\
\hline Alporas & 25 & 0.20 & 0.08 & 3.5 & 0.30 \\
& 25 & 0.30 & 0.11 & 3.5 & 0.39 \\
& 25 & 0.40 & 0.15 & 3.5 & 0.53 \\
Alcan & 75.0 & 0.15 & 0.06 & 11.5 & 0.31 \\
& 48.0 & 0.27 & 0.10 & 6.8 & 0.37 \\
& 51.0 & 0.33 & 0.12 & 5.5 & 0.43 \\
\hline
\end{tabular}


specimen by electric discharge machining to give a root diameter of $0.1 \mathrm{~mm}$ and height $0.1 \mathrm{~mm}$. Other specimen dimensions were based on ASTM E399-90 and ASTM E813-89 standards [19,20]. The specimens were aligned such that the crack propagated in the $\mathrm{L}-\mathrm{T}$ direction.

An accurate determination of the fracture toughness depends upon the reliable measurement of crack length. The DC potential drop technique was used, since it is able to measure crack length to an accuracy of $0.01 \mathrm{~mm}$ and can do so continuously as the crack advances. Accordingly, a constant 3A direct current was passed through the fracture specimens and the potential drop across the notch was monitored, taking precautions to achieve high sensitivity and stability [14,21-23].

The accuracy of the potential drop method was checked against visual observations of crack advance using a travelling microscope, and the back face strain compliance technique. The unloading compliance method was used, as recommended by the $J_{\text {IC }}$ standard, ASTM E813-89 [20], and the usual closed form relationship between crack length and the back face strain [21,24] was employed. The crack length measured by the potential drop technique was in good agreement with the observed crack length and with the inferred crack length by the unloading compliance technique.

\section{Unnotched material: mechanical properties and energy absorption}

Typical stress-strain curves are shown in Fig. 2(a) for the Alporas foam and in Fig. 2(b) for the Alcan foam. We note that the overall shapes of the tensile and compressive stress-strain curves are insensitive to the choice of material. Alporas foam was found to be almost isotropic, with a variation of $\pm 15 \%$ in modulus and yield strength with regard to specimen orientation. In contrast, the Alcan foam is orthotropic; the tensile and compressive stiffness and strength are least in the through-thickness (TT) direction.

In compression, both foams show a local peak stress at yield, followed by a fairly constant plateau stress. The plateau stress $\sigma_{\mathrm{pl}}$ was taken as the average compressive stress for compressive nominal strains within the range $5-30 \%$. In tension, both materials strain harden within the plastic range, prior to tearing at a strain of only a few percent. We found that the ultimate tensile strength $\sigma_{\mathrm{UTS}}$ is within $25 \%$ of the compressive plateau stress $\sigma_{\mathrm{pl}}$ for both foams. The unloading Young's modulus $E$ in both tension and compression tests was measured from the slope of the unloading curve after a small plastic strain, of the order of $1 \%$; it was found that the tensile and compres- sive unloading moduli are equal, for each of the foams. Fig. 3(a) and (b) summarise the measured unloading modulus $E$ and yield strength $\sigma_{\mathrm{pl}}$ plotted against $\bar{\rho}$. A power-law dependence of $E$ and of $\sigma_{\mathrm{pl}}$ upon $\bar{\rho}$ is noted, with an exponent in the range 1.8-2.2 for modulus, and in the range 1.3-2.1 for strength. In view of the scatter in measured stiffness and strength, particularly for the Alcan foam, the numerical values for these exponents are estimates only. The scatter appears to be associated with the high degree of heterogeneity of microstructure; for the Alcan foam, a strong gradient of density also exists in the thickness direction, as reported previously by Olurin et al. [15]. In general, the Alporas foam is stiffer and stronger than the Alcan foam, at a given relative density.

The energy absorption of a foam is related to the area under the compressive stress-strain $(\sigma-\varepsilon)$ curve:

$U=\int_{0}^{\varepsilon_{\mathrm{D}}} \sigma \mathrm{d} \varepsilon$

where $U$ is the energy absorbed per unit initial volume up to the densification strain $\varepsilon_{\mathrm{D}}$. Here, we shall take $\varepsilon_{\mathrm{D}}$ as the nominal compressive strain at which the nominal compressive stress equals twice the plateau value $\sigma_{\mathrm{pl}} . U$ is plotted against the compressive plateau stress $\sigma_{\mathrm{pl}}$ in Fig. 4 for both foams. The energy absorption efficiency $\xi$ is defined as the ratio of energy absorbed by an ideal energy absorber to that absorbed by the actual foam:

$\xi=\frac{\sigma_{\mathrm{pl}} \varepsilon_{\mathrm{D}}}{U}$

The efficiency was independent of relative density for each foam, and the average values are summarised in Table 2. The lower efficiency of Alcan foam in the through-thickness direction reflects the strong density gradient in this direction. Honeycombs, for comparison, have an efficiency between 88 and $96 \%$, though they are, of course, exceedingly anisotropic.

Predictions of the stiffness and strength models of Section 2 require data for the cell wall modulus $E_{\mathrm{s}}$, yield strength $\sigma_{\mathrm{y}}$ and density $\rho_{\mathrm{s}}$. We took $E_{\mathrm{s}}=70 \mathrm{GPa}$, $\rho_{\mathrm{s}}=2700 \mathrm{~kg} \mathrm{~m}^{-3}, \phi=0.75$, and $\sigma_{\mathrm{y}}=160 \mathrm{MPa}$ for the Alporas foam and $250 \mathrm{MPa}$ for the Alcan foam; these values were derived from microstructural observations and from microhardness measurements of the cell edges. Table 3 shows a comparison between the predicted and measured stiffness and strength. It is clear that the stiffness and strength of the two foams are significantly less than the predictions (1) and (2), which were derived and validated for polymeric foams. The discrepancy is ascribed to the high level of imperfection within the metallic foams (e.g. missing cells, cell wall waviness and curvature, holes, fractured cell walls, inclusions and non-uniformity of local density). 
(a)

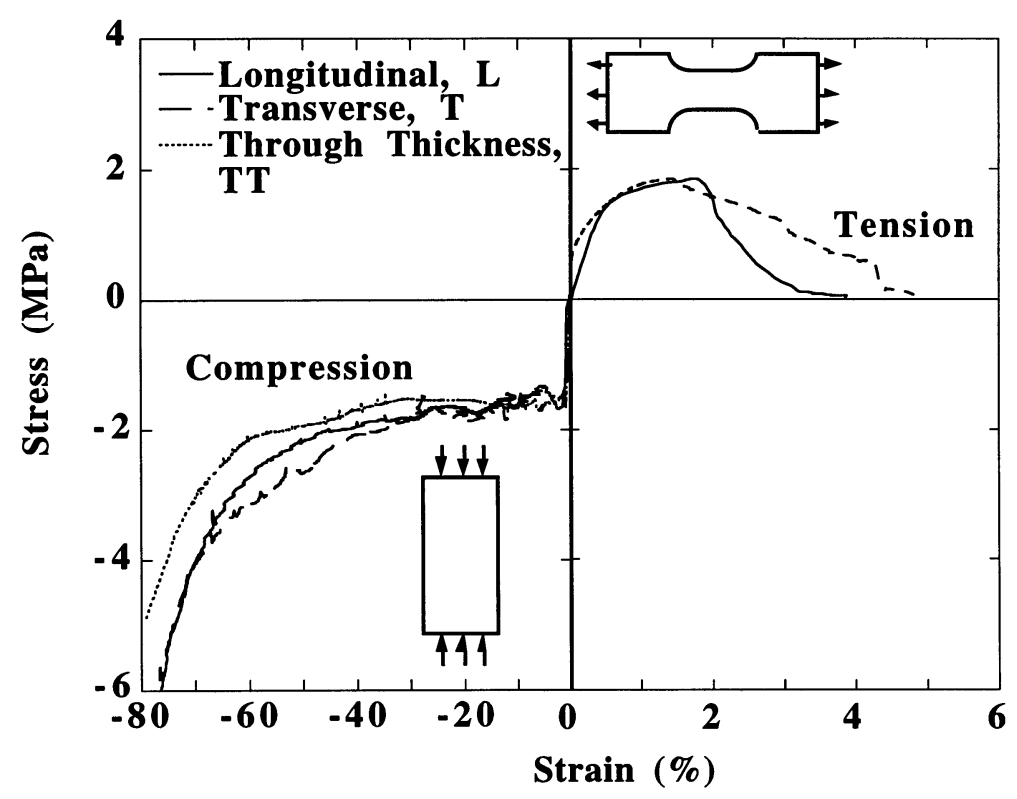

(b)

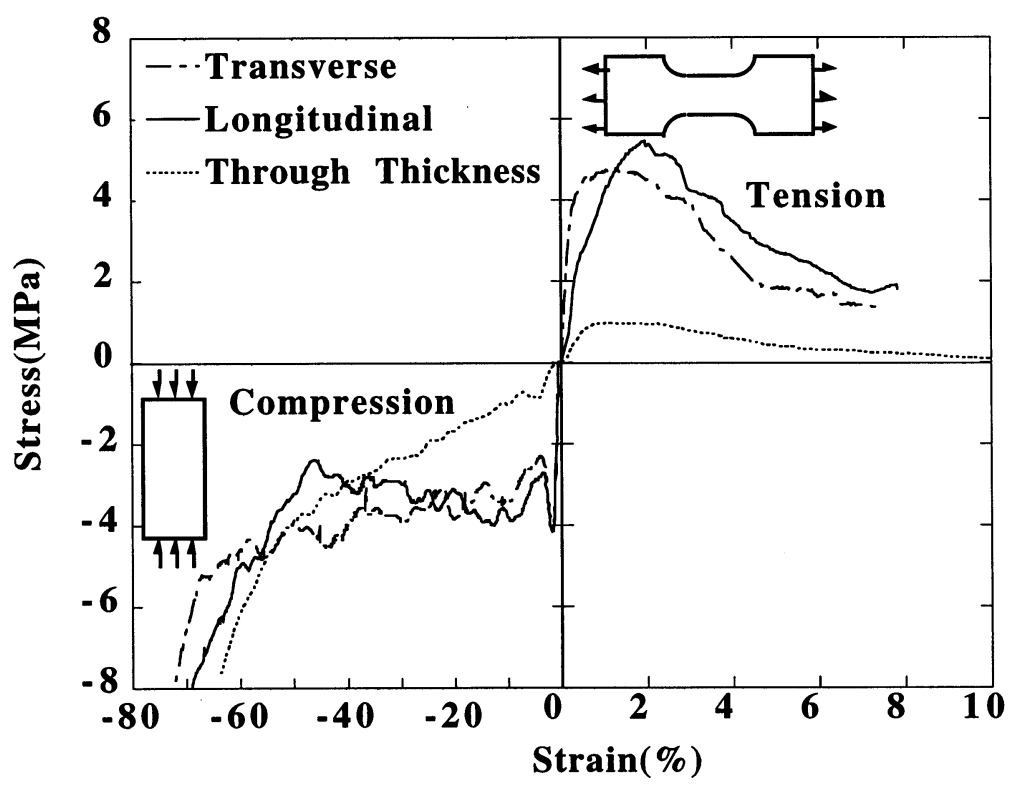

Fig. 2. Tensile and compressive monotonic responses of (a) Alporas foam, $\bar{\rho}=0.11$, and (b) Alcan foam, $\bar{\rho}=0.12$.

5. Notched material: tensile and compressive responses for deep sharp notches

The effect of notch length $a_{0}$ upon the tensile and compressive strengths of deep double edge notched specimens are shown in Fig. 5(a) for Alporas foam and in Fig. 5(b) for the Alcan foam. The plots display the net section stress versus the plastic displacement, $\Delta u=u-$ $u_{\mathrm{el}}$ (where $u$ is the total displacement across the notch and $u_{\mathrm{el}}$ is the elastic load-line displacement). For both tensile and compressive tests, the net section stresses exceed the yield strength of the unnotched materials, which implies a small degree of notch strengthening associated with plastic constraint. The increased strength with reduced net section may also be due to a reduced probability of material imperfection with diminishing stressed volume.

It is noted from Fig. 5(a) and (b) that the net section stress drops to zero in the tensile tests at an opening 
displacement $\Delta u=1-2 \mathrm{~mm}$ for both foams. The displacement $\Delta u$ at fracture is almost independent of $a / W$ for the Alcan foam, see Fig. 5(b); for Alporas foam, it decreases by about a factor of 2 when $a / W$ is increased from 0 to 0.6 , refer to Fig. 5(a). In contrast, the compressive net section stress remains almost constant with increasing deformation; the tests were terminated before the notch faces came into contact. A similar response has been observed previously [13] in deep notch compression tests on the Alporas foam.

(a)

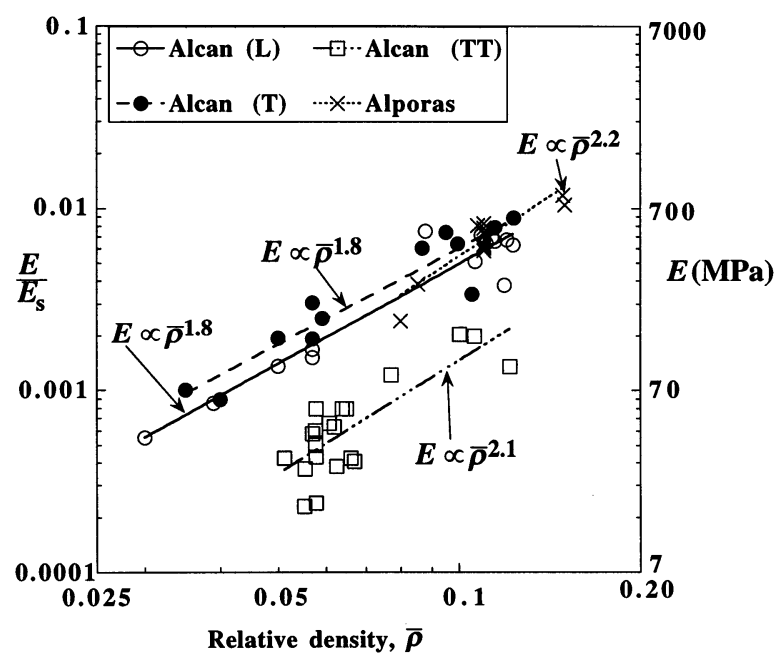

(b)

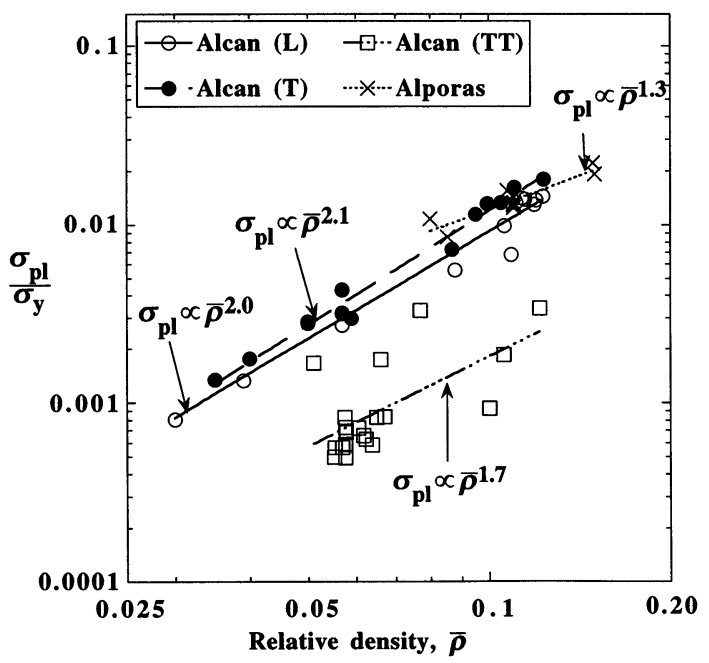

Fig. 3. Effect of relative density $\bar{\rho}$ upon (a) unloading modulus, and (b) compressive plateau strength for Alporas and Alcan foams.

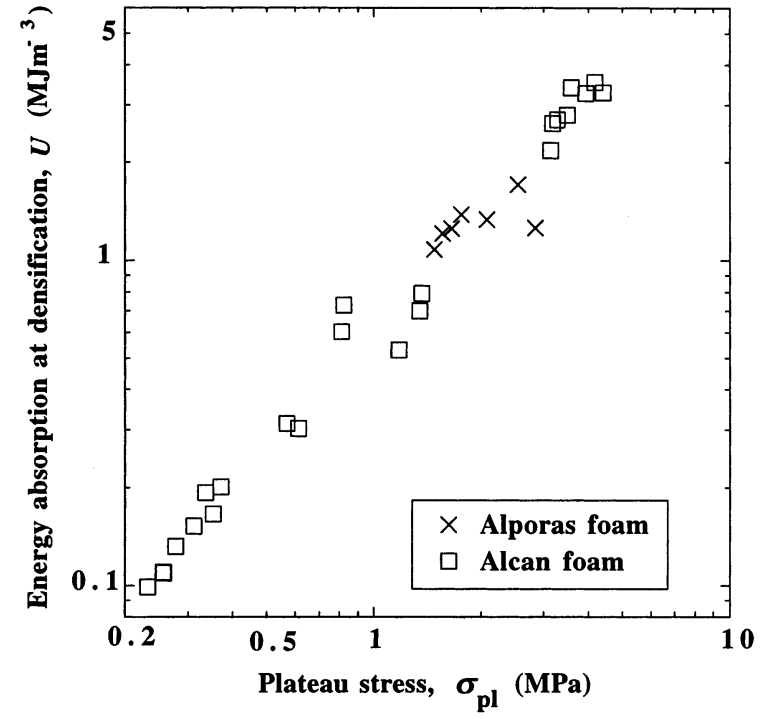

Fig. 4. Energy absorption of Alporas and Alcan foams at a compressive nominal strain, $\varepsilon_{\mathrm{D}}$.

Table 2

Energy absorption efficiency at densification

\begin{tabular}{lll}
\hline Material & Direction & Energy absorption efficiency (\%) \\
\hline Alcan & TT & 65 \\
& T & 89 \\
& L & 95 \\
Alporas & L, T and TT & 84 \\
\hline
\end{tabular}

\section{Fracture toughness tests}

\subsection{Test validity}

Limitations on the available thickness of metallic foams and size limitations on the available test machine precluded the use of a valid $K_{\mathrm{IC}}$ plane strain fracture toughness test [19], and so the $J$-integral test [20,25-27] was used instead. Three alternative $J$-integral test procedures exist in the literature: the ASTM standard ASTM E813-89 for the determination of $J_{\text {IC }}$ [20], the $J-R$ standard ASTM E1152-87 [27], and the modified $J$-integral $J_{\mathrm{M}}$ test [28]. McCullough et al. [14] have already compared these three tests methods for an aluminium alloy foam, Alulight, and they find identical measurements of the $J$-curve to within experimental scatter. A similar finding was obtained from preliminary tests on Alporas foam, hence the ASTM Standard E813-89 [20] was adopted due to its relative simplicity.

Typical $J$-integral test results are shown in Fig. 6(a) for compact tension specimens made from Alporas foam of relative density $\bar{\rho}=0.15$, and width $W=100$ $\mathrm{mm}$ and $W=200 \mathrm{~mm}$. The responses of the two specimens are essentially the same for a crack extension $\Delta a<10 \mathrm{~mm}$; at greater crack extensions the responses 
Table 3

Comparison of the predicted and measured values for $E, \sigma_{\mathrm{pl}}$ and $\varepsilon_{\mathrm{D}}$

\begin{tabular}{|c|c|c|c|c|c|c|c|c|}
\hline \multirow{2}{*}{$\begin{array}{l}\text { Material } \\
\text { (Direction) }\end{array}$} & \multirow{2}{*}{$\begin{array}{l}\text { Density } \rho \\
\left(\mathrm{Mg} \mathrm{m}^{-3}\right)\end{array}$} & \multirow{2}{*}{$\begin{array}{l}\text { Relative density } \\
\bar{\rho}\end{array}$} & \multicolumn{3}{|l|}{ Predicted } & \multicolumn{3}{|l|}{ Measured } \\
\hline & & & $E(\mathrm{GPa})$ & $\sigma_{\mathrm{pl}}(\mathrm{MPa})$ & $\varepsilon_{\mathrm{D}}($ nominal $)$ & $E(\mathrm{GPa})$ & $\sigma_{\mathrm{pl}}(\mathrm{MPa})$ & $\varepsilon_{\mathrm{D}}$ (nominal) \\
\hline \multicolumn{9}{|l|}{ Alporas } \\
\hline (TT) & 0.20 & 0.08 & 1.51 & 2.87 & 0.90 & 0.22 & 1.39 & 0.68 \\
\hline (L) & 0.30 & 0.11 & 2.31 & 4.27 & 0.85 & 0.46 & 1.65 & 0.65 \\
\hline (TT) & & & & & & 0.47 & 1.73 & 0.65 \\
\hline (T) & & & & & & 0.47 & 1.65 & 0.65 \\
\hline (TT) & 0.40 & 0.15 & 3.46 & 6.16 & 0.79 & 0.78 & 2.46 & 0.58 \\
\hline \multicolumn{9}{|l|}{ Alcan } \\
\hline (T) & 0.09 & 0.03 & 0.66 & 2.13 & 0.95 & 0.06 & 0.48 & 0.89 \\
\hline (L) & & & & & & 0.05 & 0.39 & 0.86 \\
\hline (T) & 0.15 & 0.06 & 1.13 & 4.47 & 0.92 & 0.17 & 1.21 & 0.77 \\
\hline (L) & & & & & & 0.11 & 0.96 & 0.81 \\
\hline (TT) & & & & & & 0.04 & 0.25 & 0.48 \\
\hline (T) & 0.27 & 0.10 & 2.12 & 7.79 & 0.86 & 0.43 & 4.73 & 0.74 \\
\hline (L) & & & & & & 0.35 & 3.58 & 0.75 \\
\hline (TT) & & & & & & 0.14 & 0.77 & 0.51 \\
\hline (T) & 0.33 & 0.12 & 2.72 & 9.53 & 0.83 & 0.50 & 5.05 & 0.71 \\
\hline (L) & & & & & & 0.41 & 4.44 & 0.72 \\
\hline (TT) & & & & & & 0.19 & 1.10 & 0.47 \\
\hline
\end{tabular}

diverge. On recalling that the ASTM standard E115287 [27] stipulates an allowable crack extension $\Delta a$ of less than $0.1 c_{0}$, where $c_{0}=W-a_{0}$ is the uncracked ligament dimension, we must disregard the data for $\Delta a>7 \mathrm{~mm}$ for the case $c_{0}=70 \mathrm{~mm}(W=100 \mathrm{~mm})$; similarly, we must disregard the data for $\Delta a>$ $14 \mathrm{~mm}$ for the $c_{0}=140 \mathrm{~mm}(W=200 \mathrm{~mm})$ specimen. The blunting line $J=2 \sigma_{\mathrm{pl}} \Delta a$ has been added to Fig. 6(a): its point of intersection with the $J-\Delta a$ curve provides a provisional value for $J_{\mathrm{IC}}$. In all subsequent tests reported, the specimen thickness $B$ and uncracked ligament $c=W-a$ were sufficiently large for the size criterion to be met and so the provisional value of $J_{\mathrm{IC}}$ is valid.

The $J_{\text {IC }}$ standard recommends that the initial notch be sharpened by pre-cracking in fatigue. Preliminary tests were performed to compare the fracture toughness response of fatigue pre-cracked specimens with those of specimens spark machined with notch root diameters in the range $1-10 \mathrm{~mm}$. We found that a spark-machined notch gave the same fracture response as a fatigue pre-cracked specimen provided the notch root diameter was less than the average cell size. It is concluded that notches of small initial opening are blunted to an opening of one cell size. When the notch root diameter exceeds the average cell size, the measured toughness is increased, and is unrepresentative of the material toughness (see Fig. 6(b)). Unless otherwise stated, the fracture results presented herein are for specimens that were spark machined to an initial notch opening of 0.1 $\mathrm{mm}$, which is less than the cell size of $3.5 \mathrm{~mm}$ for Alporas foam and 5-12 $\mathrm{mm}$ for the Alcan foam.

\subsection{Effect of relative density upon the $R$-curve}

Visual observations of crack growth in the $J$-tests reveal that cell edge ligaments bridge the crack. It is argued that the bridging ligaments are the source of the $R$-curve behaviour. With continuous crack extension, $J$ increases until a steady-state toughness $J_{\text {ss }}$ is attained, see Fig. 6(a). The effect of relative density $\bar{\rho}$ upon the $R$-curve behaviour is plotted in Fig. 7(a) for the Alporas foam, and in Fig. 7(b) for the Alcan foam. As expected, the $J$-resistance curves increase in magnitude with increasing $\bar{\rho}$. The dependence of $J_{\mathrm{IC}}$ and $J_{\mathrm{ss}}$ upon $\bar{\rho}$ is shown explicitly in the $\log -\log$ plots of Fig. 7(c) for the Alporas foam, and Fig. 7(d) for the Alcan foam: both $J_{\text {IC }}$ and $J_{\text {ss }}$ vary with $\bar{\rho}$ to the power of about 1.5 for each foam. The scatter in the measured $J_{\mathrm{IC}}$ and $J_{\mathrm{ss}}$ values versus $\bar{\rho}$ is much less than that observed for uniaxial tensile and compressive strengths, as summarised in Fig. 3(a) and (b). This reduced scatter is due to the fact that the CT specimens are much larger than the specimens for the uniaxial tests.

In order to compare the predictions of the fracture toughness models of Section 2 with the measured toughness data, we need to convert the $J_{\text {IC }}$ values to $K_{\mathrm{IC}}$ values using the well-known Irwin relation $K_{\mathrm{IC}}=$ $\sqrt{\bar{E} J_{\text {IC }}}$ where $\bar{E}$ is the plane strain value of Young's modulus. We have measured Young's modulus for each foam via the unloading compliance of the compact tension specimens, and used these measured values in the calculation of $K_{\mathrm{IC}}$. Good agreement was observed between these measured values from the $\mathrm{CT}$ specimens and the values measured in the uniaxial tests along the 
$\mathrm{L}$ and $\mathrm{T}$ directions, as already reported in Fig. 3(a). The scatter however is much less for the CT specimens, due to their large size. The Poisson's ratio $v$ of the foams was found to be about $v=0.2$, and this value was used in order to calculate the plane strain modulus $\bar{E}$ from the plane stress value $E$, according to $\bar{E} \equiv E /\left(1-v^{2}\right)$.

Results for $K_{\mathrm{IC}}$ are included in Fig. 7(c) and (d). We note that $K_{\mathrm{IC}}$ varies with $\bar{\rho}$ to the power of approximately 1.5 for both foams. These dependencies support the notion that the foams behave as open cell foams [1].

The prediction (4) for $K_{\mathrm{IC}}$ is included in Fig. 7(c) and (d). For Alporas foam, the predicted value of $K_{\mathrm{IC}}$ varies with the relative density to the power of 1.5 , whereas for the Alcan foam, a simple power law is not obtained, due to the dependence of cell size $\ell$ upon $\bar{\rho}$. The prediction (Eq. (4)) is able to capture the functional dependence of $K_{\mathrm{IC}}$ upon $\bar{\rho}$, but underpredicts $K_{\mathrm{IC}}$ by a

(a)

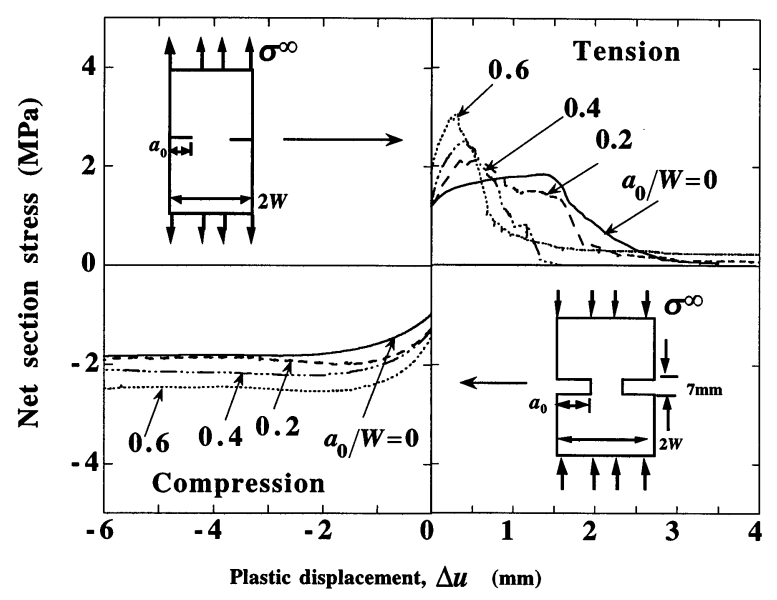

(b)

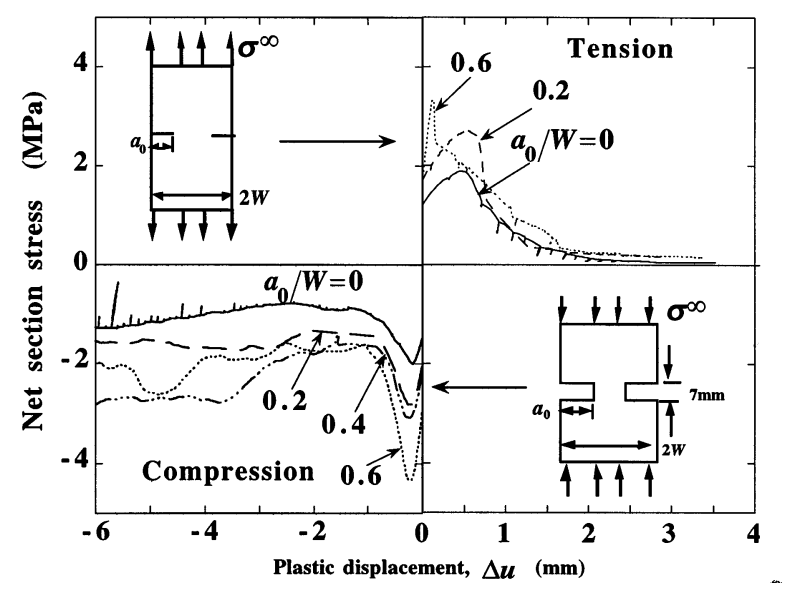

Fig. 5. Tensile and compressive net section stress versus plastic displacement for (a) Alporas foam $\bar{\rho}=0.11,2 W=60 \mathrm{~mm}$, and (b) Alcan foam $\bar{\rho}=0.075,2 W=60 \mathrm{~mm}$. For both materials the initial notch length $a_{0}$ is varied from zero to $0.6 \mathrm{~W}$. (a)

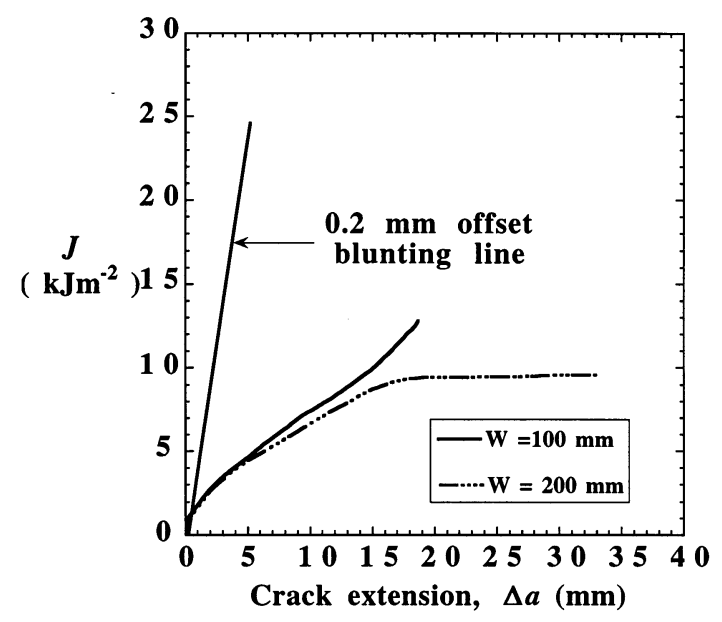

(b)

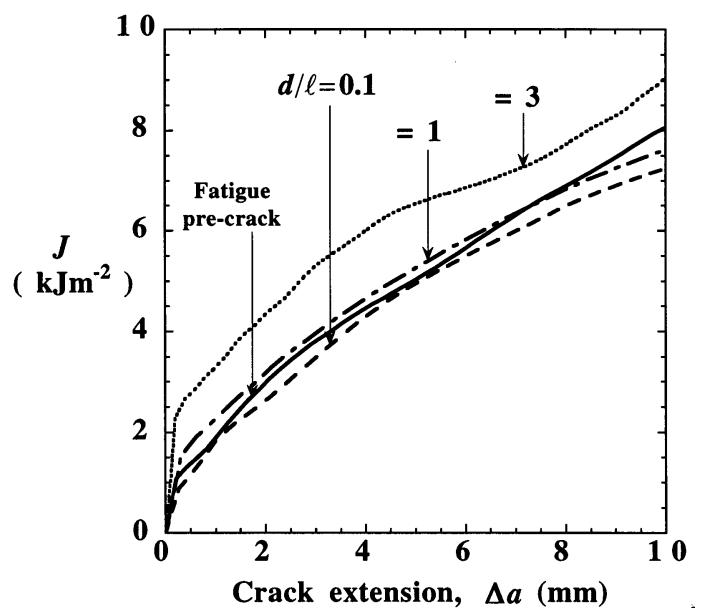

Fig. 6. (a) Effect of width $W$ of compact tension specimen upon the measured $J$-curve for Alporas foam, $\bar{\rho}=0.15, a_{0} / W=0.3, B=25$ $\mathrm{mm}$, and (b) Effect of notch root diameter $d$ on the measured $J$-curve for Alporas foam, $\bar{\rho}=0.15, a_{0} / W=0.3, B=25 \mathrm{~mm}$ and $W=100$ $\mathrm{mm}$. The cell size $\ell$ of Alporas foam is $\ell=3.5 \mathrm{~mm}$.

factor of about two for Alporas foam and overpredicts by a factor of about two for the Alcan foam. The Alcan foam is more heterogeneous and brittle than the Alporas foam, and contains a gradient in relative density through its thickness [15].

\section{A crack bridging model}

It is instructive to employ a cohesive zone model to predict the steady state toughness $J_{\text {ss }}$. We assume that the foam behaves as an elastic solid with a cohesive zone ahead of the initial pre-crack; the tensile traction versus local crack opening displacement relation is taken to equal the net section stress versus extra dis- 
(a)

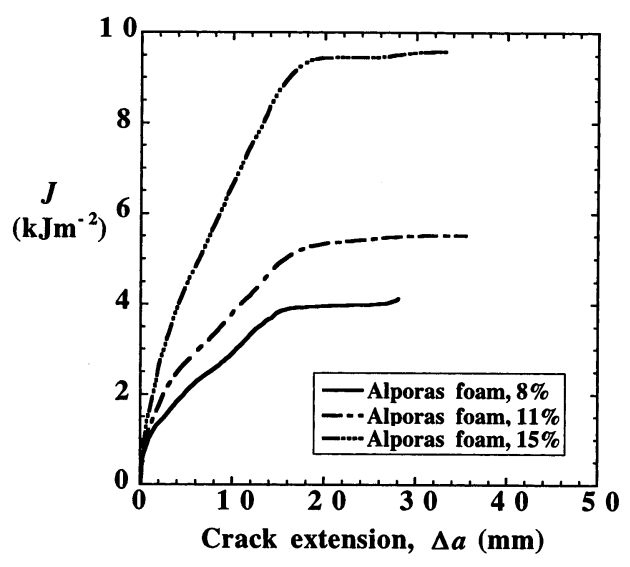

(c)

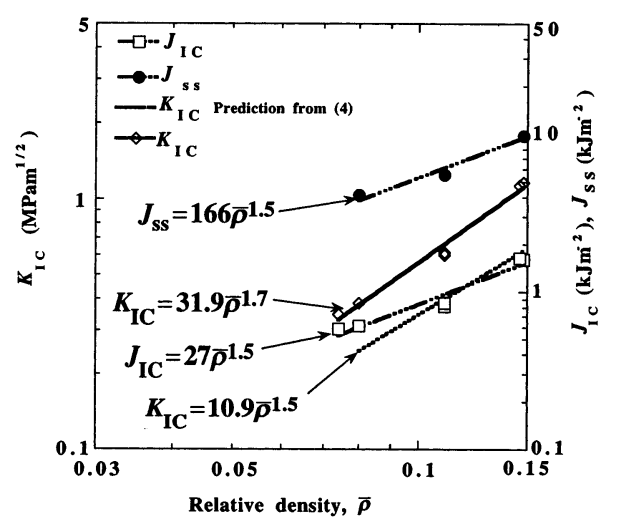

(b)

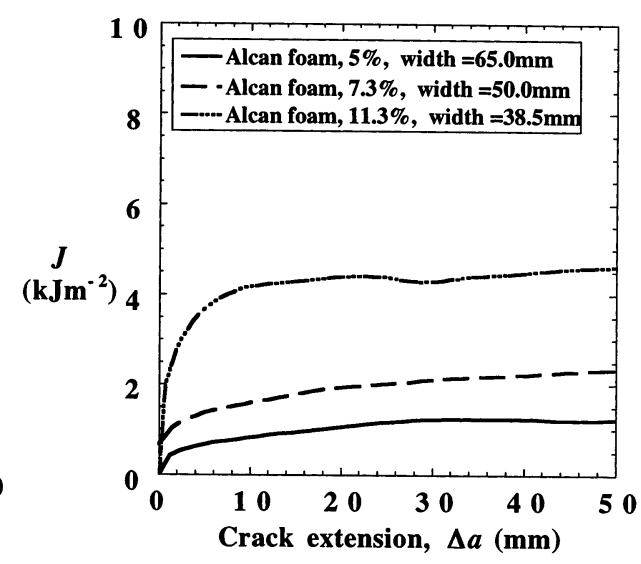

(d)

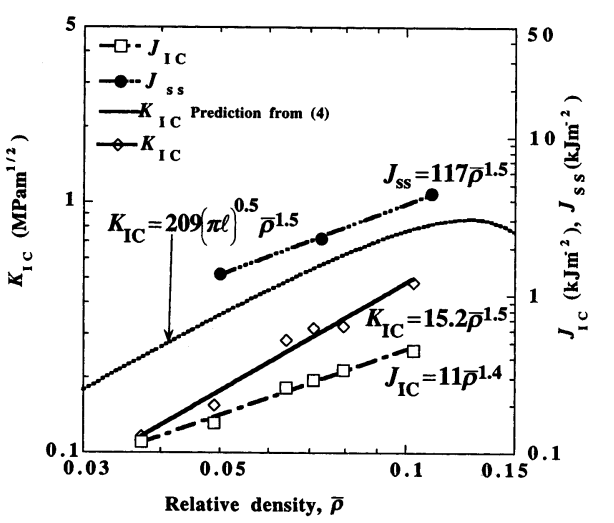

Fig. 7. $J$-resistance curves for (a) Alporas foam, and (b) Alcan foam, for a range of relative density $\bar{\rho}$. Effect of relative density $\bar{\rho}$ upon the toughness measures $J_{\mathrm{IC}}, J_{\mathrm{ss}}$ and $K_{\mathrm{IC}}$ for (c) Alporas foam, and (d) Alcan foam. The Alporas foam compact tension specimens are of thickness $B=25 \mathrm{~mm}$ and width $W=200 \mathrm{~mm}$; the Alcan foam specimens are of width $W=300 \mathrm{~mm}$, and of thickness $B=65 \mathrm{~mm}$ for $\bar{\rho}=0.05, B=50 \mathrm{~mm}$ for $\bar{\rho}=0.07$, and $B=38.5 \mathrm{~mm}$ for $\bar{\rho}=0.11$.

placement $\Delta u$ in the deep notch tests of Fig. 5. Then, $J_{\mathrm{ss}}$ equals the work of fracture $W_{\mathrm{f}}$, as defined by the area under the traction versus $\Delta u$ curve $^{3}$, see Rice [29]. The comparison of $J_{\mathrm{ss}}$ and $W_{\mathrm{f}}$ is shown in Fig. 8(a) for the Alcan and Alporas foams; data are included for an Alulight aluminium alloy foam [14], and for a PVC foam (trade name 'Divinycell' H200) [30]. We conclude that $J_{\mathrm{ss}} \approx W_{\mathrm{f}}$ for the Alporas, Alulight and PVC foams, whereas $J_{\mathrm{ss}}$ is of the order of $50-90 \%$ of $W_{\mathrm{f}}$ for the Alcan foam. The reason for the reduced value of $J_{\mathrm{ss}} / W_{\mathrm{f}}$ for the Alcan foam is unclear.

The relationship between the steady state toughness $J_{\text {ss }}$ and the strength and cell size of the foams is

\footnotetext{
${ }^{3}$ This corrects Eq. (6.5) of McCullough et al. [14]. The error in [14] stemmed from the fact that the moment $M$ versus extra rotation $\theta^{\prime}$ for a deeply cracked beam in bending was wrongly stated in Eq. (6.5): the relation should read $\theta^{\prime}=\mathrm{f}\left(M^{1 / N} \sigma_{0}^{-1 / N} c^{-(N+2 / N)}\right)$ in the notation of [14].
}

explored in Fig. 8(b). Specifically, $J_{\mathrm{ss}} / \sigma_{\mathrm{UTS}} \ell$ is plotted against $\bar{\rho}$ for the Alcan, Alporas, Alulight and PVC foams: we find that $J_{\mathrm{ss}} / \sigma_{\mathrm{UTS}} \ell \approx 1$ for the Alporas, Alulight and PVC foams whereas $J_{\mathrm{ss}} / \sigma_{\mathrm{UTS}} \ell \approx 0.2$ for the Alcan foam. The reduced value of $J_{\mathrm{ss}} / \sigma_{\mathrm{UTS}} \ell$ for the Alcan foam is consistent with the observation that the critical opening $\Delta u$, at which the bridging traction drops to zero in the deep notch tests, is given by $\Delta u \approx 0.2 \ell$ for the Alcan foam. By comparison, the bridging traction drops to zero at $\Delta u \approx \ell$ for the Alporas, Alulight and PVC foams.

The observations of the current study give an alternative explanation to that of Sugimura et al. [13] for the underlying mechanism controlling the steady state toughness $J_{s s}$. It appears that the crack bridging strength, and critical crack opening $\Delta u$ are set by bending of the cell edges, rather than by plastic stretching of the cell faces. The supporting arguments are as follows. 
1. Eqs. (1) and (2) suggest that the strengths and moduli of a foam scales with $\bar{\rho}^{1.5}$ and $\bar{\rho}^{2}$, respectively, when the tensile behaviour is dominated by the bending of cell edges. The accumulation of experimental evidence, as given in Fig. 3 for the Alporas and Alcan foams, and as summarised by Ashby et al. [10] for a wider range of metallic foams, supports this dependence.

2. The critical tensile opening $\Delta u$ for which the net section stress drops to zero in the deep notch tests is of the order of the cell size $\ell$, rather than the thickness of the cell faces.

The steady state fracture toughness $K_{\mathrm{ss}}$ can be estimated from the following relations:

$J_{\mathrm{ss}} \approx \sigma_{\mathrm{pl}} \ell$,

$K_{\mathrm{ss}}=\sqrt{\bar{E} J_{\mathrm{ss}}}$

(a)

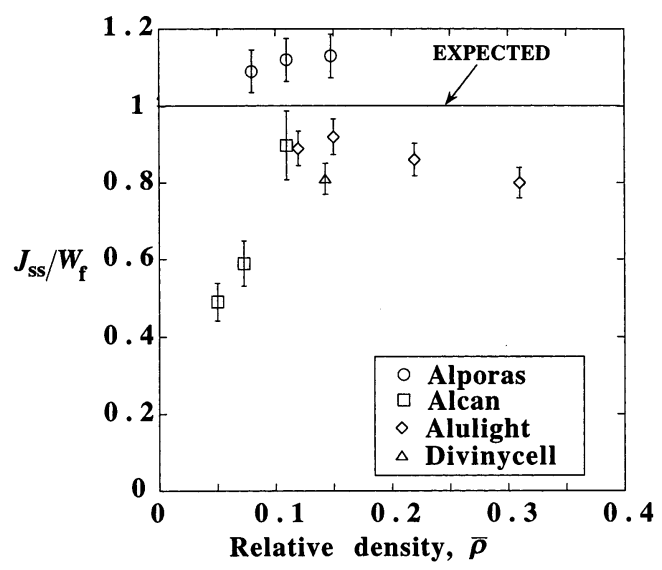

(b)

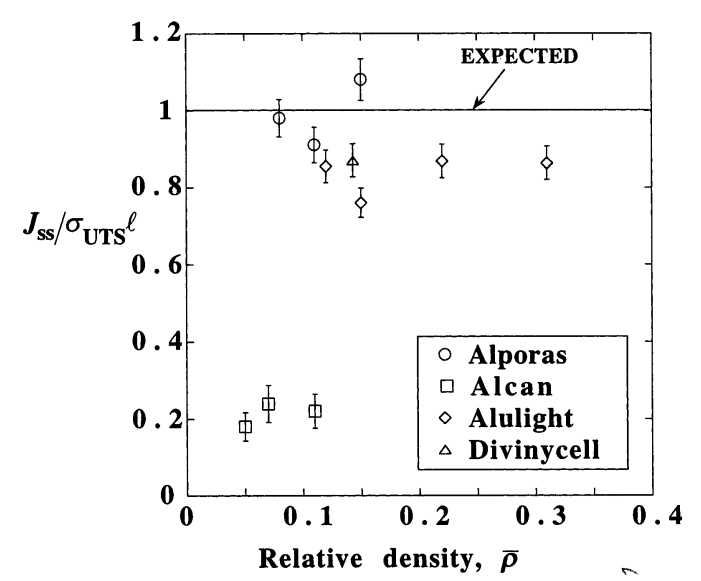

Fig. 8. (a) $J_{\text {ss }}$ against relative density $\bar{\rho}$, and (b) $J_{\text {ss }} / \sigma_{\mathrm{UTS}} \ell$ versus $\bar{\rho}$ for Alporas, Alcan and Alulight metallic foams, and Divinycell PVC foam. and

$\bar{E}=C_{1} E_{\mathrm{s}} \bar{\rho}^{2}$

where Eq. (8c) is the bending-dominated limit of Eq. (2), and the parameter $C_{1}$ is of the order of unity. Likewise, the strength $\sigma_{\mathrm{pl}}$ can be simplified from Eq. (1) to read,

$\sigma_{\mathrm{pl}}=C_{2} \sigma_{\mathrm{y}} \bar{\rho}^{1.5}$

where $C_{2}=0.3$. Combining Eqs. (8a), (8b), (8c) and (8d) gives

$K_{\mathrm{ss}} \approx \sqrt{C_{1} C_{2}} \sqrt{\sigma_{\mathrm{y}} E_{\mathrm{s}} \ell} \bar{\rho}^{1.75}$

We note the close similarity between Eq. (5) and Eq. (9), except for the difference in the exponent of $\bar{\rho}$.

\section{Concluding remarks}

This paper describes the tensile, compressive and fracture properties of two metallic foams with the trade names Alporas and Alcan. Moduli, strengths and densification strains are characterised as a function of relative density. The results, when compared with theoretical models based on idealised foam structures, reveal unexpected discrepancies. The discrepancies are caused by defects in the microstructures of the foams, the effects of which were not included in the models. Tests on samples with notches show that the properties are notch-insensitive. Also, the toughness of the aluminium alloy foams has been measured and interpreted in terms of their microstructures. A significant $R$-curve behaviour was observed: this is due to cell edges bridging the crack behind the observed crack tip. The area under the traction-plastic displacement curve for deep double edge notched specimens is in satisfactory agreement with the steady state toughness $J_{\text {ss }}$ for the Alporas foam.

\section{Acknowledgements}

The authors are grateful to DARPA/ONR for their financial support through MURI grant number N00014-1-96-1028 on the Ultralight Metal Structures project at Harvard University, to T.J. Lu and to A. Heaver and S. Marshall for their technical assistance.

\section{References}

[1] L.J. Gibson, M.F. Ashby, Cellular Solids: Structure and Properties, 2nd edition, Cambridge University Press, Cambridge, UK, 1997.

[2] A.E. Simone, L.J. Gibson, Acta Mater. 46 (1998) 3109-3123.

[3] L.D. Kenny, Mater. Sci. Forum 217-222 (1998) 1883-1890. 
[4] I. Jin, D. Kenny, H. Sang, Method of producing lightweight foamed metal, U.S. Patent No. 4973 358, 1990.

[5] S. Akinyama, S. Ueno, K. Imagawa, A. Kitahara, S. Nagata, K.M. Amagasaki, T.N. Amagasaki, M.I. Amagasaki, Foamed metal and method of producing same, U.S. Patent No. 4713 277, 1987

[6] J. Banhart, J. Baumeister, in: D.S. Schwartz, D.S. Shih, A.G. Evans, H.N.G. Wadley (Eds.), Materials Research Society Symposium, vol. 521, MRS, Warrendale, PA, 1998, pp. 121-131.

[7] Ahmad Falahati, Feasibility study for the production of iron-based metallic foams, Technische University, Wien, Austria, 1997 Master Thesis.

[8] G.J. Davies, Shu Zhen, J. Mater. Sci. 18 (1983) 1899-1911.

[9] H.D. Kunze, J. Baumeister, J. Banhart, M. Weber, Pow. Metall. Int. 25 (1993) 182-185.

[10] M.F. Ashby, A.G. Evans, N.A. Fleck, L.J. Gibson, J.W. Hutchinson, H.N.G. Wadley, Metal Foams: A Design Guide, Butterworth-Heinemann, Oxford, UK, 2000.

[11] R. Brezny, D.J. Green, J. Am. Ceram. Soc. 76 (1993) 2185-2192.

[12] J.S. Huang, L.J. Gibson, Acta Mater. 39 (1991) 1627-1636.

[13] Y. Sugimura, J. Meyer, M.Y. He, H. Bart-Smith, J. Grenestedt, A.G. Evans, Acta Mater. 45 (1997) 5245-5259.

[14] K.Y.G. McCullough, N.A. Fleck, M.F. Ashby, Acta Mater. 47 (1999) 2331-2344.

[15] O.B. Olurin, N.A. Fleck, M.F. Ashby, in: J. Banhart, M.F. Ashby, N.A. Fleck (Eds.), Metfoam '99, Bremen, Germany, MIT Press, 1999, pp. 365-372.

[16] A.M. Murphy, M.F. Ashby, N.A. Fleck, Metallography and image analysis of metallic foams, Cambridge University Engineering Department, 1997 Technical Report, CUED/CMICROMECH/TR.1, December.

[17] Alcan Aluminium Corporation R\&D, Standards test method for compressive properties of porous metallic metals (draft), Unpublished Document, 1997.
[18] E.W. Andrews, G. Gioux, P. Onck, L.J. Gibson, Int. J. Mech. Sci. (2000) submitted for publication.

[19] ASTM E399-90, Standard test method for plane strain fracture toughness of metallic materials, American Society of Testing and Materials, 1990

[20] ASTM E813-89, Standard test method for $J_{\text {IC }}$ : a measure of fracture toughness, American Society of Testing and Materials, 1989.

[21] N.A. Fleck, in: K.J. Marsh, R.A. Smith, R.O. Ritchie (Eds.), Fatigue Cracks Measurements: Techniques and Applications, EMAS, UK, 1991, pp. 69-93.

[22] N.A. Fleck, An Investigation of Fatigue Crack Closure, Cambridge University Engineering Department, Cambridge, UK, 1984 Ph.D. Thesis.

[23] M.D. Halliday, C.J. Beevers, in: C.J. Beevers (Ed.), The Measurements of Crack Length and Shape During Fracture and Fatigue, EMAS, UK, 1980, pp. 85-112.

[24] C.E. Richards, W.F. Deans, in: C.J. Beevers (Ed.), The Measurements of Crack Length and Shape During Fracture and Fatigue, EMAS, UK, 1980, pp. 28-68.

[25] T.L. Anderson, Fracture Mechanics: Fundamentals and Applications, second ed., CRC Press, Boca Raton, FL, 1994.

[26] R.H. Hertzberg, Deformation and Fracture Mechanics of Engineering Materials, fourth ed., Wiley, New York, 1995.

[27] ASTM E1152-87, Standard test methods for determining $J-R$ curves, American Society of Testing and Materials, 1987.

[28] H.A. Ernst, ASTM STP 803 (1981) 191-213.

[29] J.R. Rice, in: H. Liebowitz (Ed.), Fracture: An Advanced Treatise: Mathematical Fundamentals, vol. 2, 1968, pp. 191-311.

[30] O.B. Olurin, Deformation and Fracture of Cellular Foams, Cambridge University Engineering Department, Cambridge, UK, 2000 Ph.D. Thesis. 